\title{
Definitely, maybe: A new experimental paradigm for investigating the pragmatics of evidential devices across languages
}

\author{
Judith Degen a, *, Andreas Trotzke ${ }^{\text {b }}$, Gregory Scontras ${ }^{\text {c }}$, Eva Wittenberg ${ }^{\text {d }}$, \\ Noah D. Goodman ${ }^{\mathrm{e}}$
}

a Department of Linguistics, Stanford University, 450 Serra Mall, Stanford, CA 94305, USA

b Department of Linguistics, University of Konstanz, Universitätsstraße 10, 78457 Konstanz, Germany

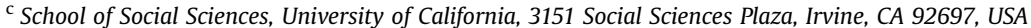

d Department of Linguistics, UCSD, 9500 Gilman Drive, La Jolla, CA 92093-0108, USA

e Department of Psychology, Stanford University, 450 Serra Mall, Stanford, CA 94305, USA

Keywords:

Discourse particles

English

Evidentials

German

Modals

Psycholinguistics

\begin{abstract}
A B S T R A C T
We present a new experimental paradigm for investigating lexical expressions that convey different strengths of speaker commitment. Specifically, we compare different evidential contexts for using modal devices, epistemic discourse particles, and statements with no evidential markers at all, examining the extent to which listeners' interpretations of certain types of evidential words and their judgments about speaker commitment differ in strength. We also probe speakers' production preferences for these different devices under varying evidential circumstances. The results of our experiments shed new light on distinctions and controversies that play a key role in the current theoretical literature on the semantics and pragmatics of modals and discourse particles. Our paradigm thus contributes to a domain of experimental research on evidential expressions that is only just taking shape at the crossroads of theoretical semantics/pragmatics and psycholinguistics; we provide a potential starting point for approaching theoretical debates on the nature of modal evidential expressions from an experimental and context-oriented perspective.
\end{abstract}

\section{Introduction}

Recent years have seen a rapid development in typological and empirical semantic research on evidential expressions across languages (see, e.g., Korotkova, 2016; Matthewson, 2012; Murray, 2017). Within this growing body of research, we observe a trend towards experimental attempts to systematically explore different aspects of the use of evidential devices (see Knobe and Yalcin, 2014; Lassiter, 2016; Ünal and Papafragou, 2018). The series of experiments we present in this paper contributes to this type of empirical research by providing a new experimental paradigm for investigating lexical expressions that convey different strengths of speaker commitment. In particular, we introduce a methodology for exploring the impact of different evidential circumstances on the use of modal evidentials, epistemic discourse particles, and statements with no

\footnotetext{
* Corresponding author.

E-mail addresses: jdegen@stanford.edu (J. Degen), andreas.trotzke@uni-konstanz.de (A. Trotzke), gscontra@uci.edu (G. Scontras), ewittenberg@ucsd.edu (E. Wittenberg), ngoodman@stanford.edu (N.D. Goodman).
} 
evidential markers at all. We measure both production probabilities for different evidential devices under varying evidential circumstances, as well as interpretation probabilities, inferences about speaker commitment, and inferences about the evidential circumstances that generated the speaker's utterance. That is, we measure both sides of the communicative coin. In the process, we indicate how these case studies can profitably be linked to issues and controversies found in the current theoretical literature. Before turning to these issues in more detail, let us briefly sketch the evidential devices we are concerned with in this paper.

When speakers are certain about some fact expressed by a proposition $p$ (e.g., that it is raining), they are likely to communicate this fact with a simple declarative utterance, as in (1a). When they want to convey epistemic uncertainty, they have different devices for doing so: adding a modal adverbial, such as probably (1b), or using modal verbs as in (1c) and (1d). Either option leaves open the possibility that $p$ is not true.

(1) a. It is raining.

b. It is probably raining.

c. It might be raining.

d. It must be raining.

Other languages have more varied ways of conveying different degrees of speaker commitment (for an overview, see Aikhenvald, 2004). Even between closely related languages, we observe striking differences. German, for instance, is an interesting comparison case to English. While many devices for expressing speaker certainty do not differ from English- examples (2a)-(2c) are the German equivalents of (1a), (1b), and (1d)-German possesses a lexical inventory of so-called 'discourse particles', which English lacks. Consider (2d), which is an example involving the epistemic discourse particle wohl (lit. 'well'); see Zimmermann (2004) and many others:

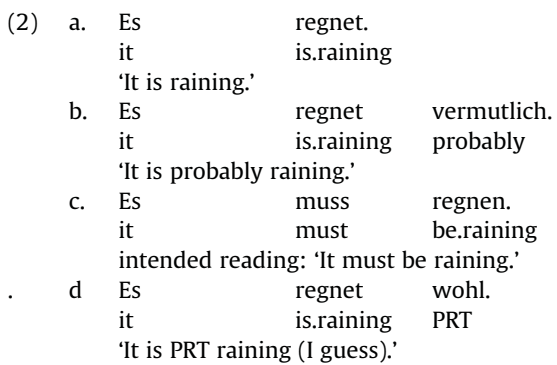

Discourse particles like wohl organize the discourse by conveying the epistemic states of both the speaker and the listener. In our case, the particle wohl communicates that the speaker merely assumes that the propositional content is true, and thus wohl lexically encodes weakened speaker commitment.

In our series of experiments below, we restrict ourselves to the epistemic/evidential words in English and German that are given in (1) and (2). In doing so, we hope to provide a focused set of experimental studies on the expression of speaker commitment that can be seen as an articulated road map for future experimental work in this domain. We are aware that our choice of evidential devices represents only a very small portion of cross-linguistic options to express different degrees of speaker commitment. However, in the next two sections, we will clarify why we chose these particular cases in English and German. We will point out to what extent experimental data on them might be interesting for claims and controversies that can be found in the current theoretical literature, and we will argue that our experiments on different degrees of speaker commitment in the domain of these evidential devices address obvious blind spots in the theoretical debates. More specifically, both empirical phenomena (epistemic must and epistemic discourse particles) are usually only discussed with regard to their theoretical status as semantic and/or pragmatic elements, and the literature does not provide a detailed picture of the evidential contexts these elements can actually be used in. For must, our data shed some light on what kind of evidential contexts can count as the relevant indirect contexts where the epistemic use of must is felicitous. For discourse particles, we explore whether particles like wohl differ in their compatibility with different evidential circumstances, compared to closely related elements like synonymous higher (i.e., speaker-oriented) adverbs.

\subsection{Issue I: evidential circumstances for using epistemic must}

The weak reading of must in (1d) above has puzzled linguistic theory for a long time already. Must serves as a strong modal of necessity, so its interpretation regarding speaker commitment should not be weaker than the plain statement without a modal in (1a); see Karttunen (1972) and subsequent work. More formally, if we assume a quantificational treatment of modality, necessity modals like must correspond to universal quantifiers over possible worlds (e.g., Kratzer, 1991). The necessity modals assert that in every (relevant) possible world, the proposition $p$ holds. Accordingly, epistemic must in (1d) should assert that in every world compatible with the speaker's knowledge, it is raining. Given that knowledge corresponds to 
justified true belief (i.e., that which is known cannot be otherwise), from (1d) it necessarily follows that it is raining (i.e., it is not possible that it is not raining). At issue, then, is the failed inference from (1d) to (1a): how could must $p$ not entail $p$ ? If it is necessarily raining, then surely it is raining. However, it appears that talking about what is necessarily the case commits speakers to less than does talking about what is actually the case.

To account for this puzzle, several different approaches have been proposed. One prominent account is the two-part theory of epistemic must from von Fintel and Gillies $(2010,2016)$. The authors propose that the necessity modal must indeed stays 'strong', with must $p$ entailing $p$. At the same time, must introduces a lexical presupposition according to which $p$ is known as a result of indirect inference. Let us briefly illustrate this idea.

Von Fintel and Gillies (2010) object to the claim that must statements like (3a) are 'weaker' than those made by the prejacent alone, (3b):

(3) a. It must be raining.

b. It is raining.

They argue that theories postulating that must serves to make weak claims in cases such as (3a) confuse the notion of indirectness with 'a feeling of weakness'. In support of this distinction, von Fintel \& Gillies provide examples such as the following (von Fintel and Gillies, 2010: 362):

(4) CONTEXT: Chris has lost her ball, but she knows with full certainty that it is either in Box A or B or C. She says:

The ball is in A or in B or in C.

It is not in $\mathrm{A}$.... It is not in $\mathrm{B}$.

So, it must be in $\mathrm{C}$.

The point of this example is that Chris knows the ball must be in one of the boxes. After excluding two of them, Chris knows conclusively that the ball is in box C. Since her knowledge is a matter of logical deduction, it can be considered indirect knowledge. Crucially, the final statement So, it must be in $C$ is then not weak at all because Chris knows with full certainty that the ball is in C. Using the modal must here thus simply expresses the indirect nature of Chris' knowledge.

Given such examples, one should reconsider the evidential contexts that were often cited to claim that must is weak. Consider the following example from von Fintel and Gillies (2010: 353):

(5) [Seeing the pouring rain]

a. It's raining.

b. ??It must be raining.

Von Fintel and Gillies (2010) argue that sentences like (5b) are not infelicitous in a context like (5) because they are too weak. Rather, according to their approach, the infelicity of $(5 \mathrm{~b})$ is due to the fact that the statement is marked as being based on indirect evidence in a context that clearly features direct evidence. Accordingly, von Fintel \& Gillies (2010) place a premium on the nature (i.e., direct vs. indirect) of the evidence. However, and importantly for our empirical approach to this debate below, the authors do not pursue an analysis that includes testing a more fine-grained set of evidence types. More specifically, although von Fintel and Gillies (2010: 354) introduce the following typology of sources of information (which is based on Willett, 1988), they state at the very beginning of their paper that epistemic modals like must are always markers of 'indirect inference' (i.e., the rightmost branch of the following figure, bolded):

(6)

Types of Sources of Information

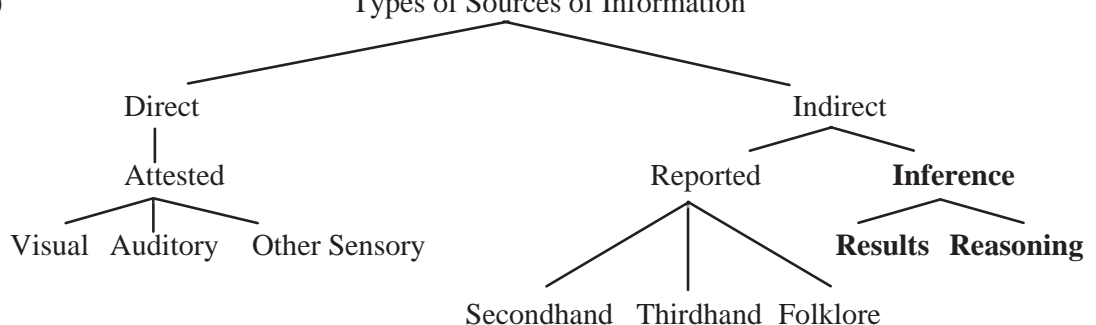

In our experiments below, we take a closer look at the evidence types that are mentioned in typologies like (6); for further more recent classifications of evidence types, see, e.g., Aikhenvald (2014) and Ünal and Papafragou (2018).

Already we see that the evidential circumstances are crucial for understanding the meaning of epistemic must (see also Matthewson, 2015). All existing approaches on epistemic must agree on this point. The question thus shifts to where one ought to locate this evidential component in the meaning of must. There are several accounts that disagree with the 
presuppositional status of this evidential component proposed by von Fintel and Gillies (2010, 2016). In particular, some argue that it should rather be considered a conventional implicature (e.g., Salmon, 2011), while others claim that it can be accounted for by Gricean reasoning. Under this latter style of approach, must is yet again treated as weak, with the evidential component of its meaning derived as a conversational implicature (Lassiter, 2014, 2016; Giannakidou and Mari, 2016; Goodhue, 2016; Mandelkern, 2017).

The experimental data we present below cannot decide between these theoretical accounts. However, if epistemic must means something like 'it follows from the evidence that', we can raise the issue of what kind of evidence (say, on a scale from first-hand observations to rather vague inference) exactly allows or even favors the use of epistemic must. This is an issue that is for the most part left open by von Fintel and Gillies (2010), who do not take into account different evidential contexts that could count as indirect evidence. Indeed, as far as we know, no systematic attempt has so far been made to test for different degrees of evidence strength in this context. Before reporting on the relevant experiments, let us now turn to the second empirical blind spot in the theoretical literature on evidential devices we are concerned with in this paper.

\subsection{Issue II: evidential circumstances for using epistemic discourse particles}

As already pointed out in example (2) above, some languages additionally feature discourse particles to express epistemic meaning components. In this domain, most work has been carried out in formal semantics (see Grosz, 2016 for a recent overview), and to date there is very little experimental work (see, however, Döring and Repp, 2016; Dörre and Trotzke, 2017).

In what follows, we will be concerned with the German discourse particle wohl (lit. 'well'). According to the literature, wohl in (6a) amounts to a quasi-synonym of epistemic muss ('must') (6b) and modal adverbs such as vermutlich ('probably') in (6c) (Grosz, 2017; Zimmermann, 2004); the particle wohl can thus be compared to our English data in interesting ways.

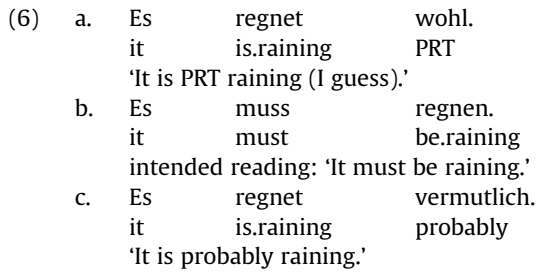

Note that particles like wohl are often viewed as a special type of adverb from a structural perspective (e.g., Cardinaletti, 2011). The claim in many formal approaches is that several properties of discourse particles derive from more general constraints on sentence adverbs (both in the syntax and in the semantics). For instance, both particles and sentence adverbs such as probably cannot occur in the surface scope of sentential negation; examples adapted from Grosz (2016: 4):

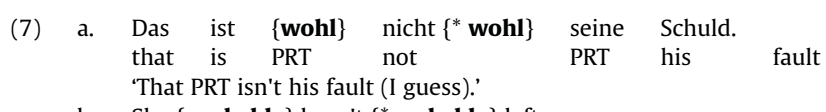

b. She \{probably $\}$ hasn't $\left\{{ }^{*}\right.$ probably $\}$ left.

However, it is well known that there are several clear-cut syntactic distinctions between sentence adverbs and discourse particles. One of the most striking structural differences is that adverbs (8a) but not discourse particles (8b) can appear in front of the finite verb in matrix clauses:

(8) a. Vermutlich ist das nicht seine
$\begin{aligned} & \text { probably is that not his } \\ & \text { 'Probably, that isn't his fault.' }\end{aligned}$
$\begin{aligned} & \text { b. } \\ & \text { 'Wohl ist das nicht seine }\end{aligned}$
$\begin{aligned} & \text { PRT Schuld. } \\ & \text { 'That isn't his fault (I guess).' }\end{aligned}$

On the semantic side, however, it is not so clear to what extent wohl differs from its modal counterparts. There are different views on how wohl might differ from adverbs and epistemic must concerning scope-taking in question formation and structured propositions (e.g., Zimmermann, 2008, 2011). Most of these differences are based on the assumption that wohl is not part of the truth-conditional content of the clause, whereas modals like must and also the epistemic contribution by adverbs such as probably contribute to truth-conditional content. Consider, for instance, the differences in the context of scope-taking in question formation. The formal sketches in (9), taken from Zimmermann (2011: 2021), make clear that using must in a question results in asking whether or not Max must necessarily be at sea, and the occurrence of probably yields a question that asks whether or not one has reason to suspect that Max is at sea: 
(9) a. $\llbracket$ Must Max be at sea? $\rrbracket=?\{$ Max must be at sea, $\neg$ (Max must be at sea) $\}$

b. $\quad \llbracket I s$ Max probably at sea? $\rrbracket=?\{\operatorname{AsSUME}(\mathrm{x}, \operatorname{Max}$ at sea $), \neg \operatorname{ASSUME}(\mathrm{x}, \operatorname{Max}$ at sea $)\}$

The point is that in both cases, the semantics of these modal devices forms part of the alternatives under discussion, according to Zimmermann (2011). The modals hence contribute to the propositional (and thus also to the truth-conditional) content of the utterance. With this observation in mind, let us now look at one example given by Zimmermann (2011: 2020) that exemplifies the scope-taking behavior of the epistemic particle wohl in questions:

\begin{tabular}{|c|c|c|c|c|c|c|}
\hline (10) & a. & $\begin{array}{l}\text { Hat } \\
\text { has }\end{array}$ & $\begin{array}{l}\text { Hans } \\
\text { Hans }\end{array}$ & $\begin{array}{l}\text { wohl } \\
\text { PRT }\end{array}$ & $\begin{array}{l}\text { Maria } \\
\text { Mary }\end{array}$ & $\begin{array}{l}\text { eingeladen? } \\
\text { invited }\end{array}$ \\
\hline
\end{tabular}

Both the translation (10a) and the formal sketch by Zimmermann (2011) in (10b) indicate that the semantics of wohl does not form part of the alternative propositions, in contrast to what we have seen in (9) for other modal devices. In particular, the question in (10a) is not asking whether or not there is a lack of commitment towards the proposition. Rather, by using wohl, the speaker wants the addressee to make their best guess concerning the alternative answers, and this can be expressed by the operator ASSUME, which takes scope over the alternative answers rather than being part of them.

Be that as it may, recall at this point that there is considerable debate in the literature on which semantic dimension is the appropriate level to account for the evidential component in the meaning of must. In other words, there are many approaches according to which the epistemic reading of must is not a truth-conditional part of utterances (see references in Section 1.1 above). Also, given the evidence for non-truth-functional views on higher adverbs discussed by Ernst (2007) and many others, one may conclude that the differences between epistemic discourse particles and other modal devices for expressing analogous meanings can clearly be seen at the level of syntax (see (7) and (8) above), while the differences are more controversial at the level of semantics (see also Grosz, 2016 on this point).

In what follows, we will abstract away from these core-semantics issues and instead add a new aspect to these debates, thereby addressing a blind spot in the theoretical literature. That is, we will approach the different modal devices mentioned above from a pragmatic (i.e., context-oriented) perspective by investigating the extent to which wohl differs from its modal counterparts in its compatibility with different evidential contexts. Although all evidential devices (epistemic must, adverbs, and discourse particles) modify the speaker's commitment to a proposition, no study to date has explored whether these (at first sight synonymous) expressions differ in their compatibility with different evidential circumstances.

In the next few sections, we will illustrate our new experimental paradigm for investigating evidential words by comparing the theoretically-challenging devices introduced in Section 1.1 and 1.2 - epistemic must and epistemic discourse particles - with other devices such as English might and probably, German vermutlich, and the unmarked bare form. In doing so, we will address the following questions: (i) Under which evidential circumstances do speakers prefer to use which evidential devices? Put differently, how do speakers use the various evidential devices? and (ii) Do listeners ascribe different strengths of speaker commitment to the use of these various linguistic devices? In other words, how do listeners interpret speakers' use of these devices? Before directly addressing these questions, we first introduce our experimental materials and obtain estimates of evidence strength. These data will then serve as the basis for the analyses that follow.

\section{Experiment 1: evidence strength}

To investigate the role of evidence strength in the production and comprehension of evidential devices, we must first generate a set of pieces of evidence that vary in how they provide support for a proposition $p$. Thus, in this section we report on an experiment that collected estimates of evidence strength with the goal of norming evidence types for a variety of characteristics that will serve as the basis for the studies to be presented below. ${ }^{1}$

\subsection{Methods}

\subsubsection{Participants}

For the English version of the experiment, 40 native English speakers were recruited through Amazon's Mechanical Turk crowd-sourcing service. For the German version, 40 German native speakers were recruited through Clickworker's crowdsourcing service. Both groups were compensated for their participation.

\footnotetext{
1 The English version of this experiment can be viewed here. The German version can be viewed here.
} 


\subsubsection{Materials and procedure}

Participants rated the probability of a state of affairs $p$ given a piece of evidence $e$ by adjusting a slider on a scale with endpoints labeled "impossible" and "absolutely certain." ${ }^{2}$ On each trial, participants first saw the following context sentence: "Imagine that you are at home." Then the evidence $e$ for $p$ was shown, for example, "Dinner is usually ready around 6pm. You look at the clock and it is 6pm." Finally, participants were asked about the probability of $p$, "How likely is it that dinner is ready?" and adjusted the slider accordingly. There were four different states of affairs $p$ that appeared in the "How likely is it that $p$ ?" frame:

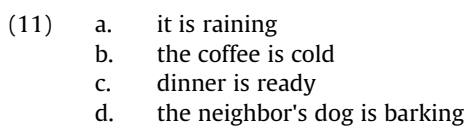

For each $p$, each participant evaluated one piece of evidence which was randomly sampled from a set of five possible pieces of evidence, resulting in four trials per participant. Trial order was randomized. For the German version, the procedure was identical; all materials were translated into German. See Appendix A for the full list of stimuli. Drawing on the classification of evidence types in (6), pieces of evidence were annotated for whether they serve as direct, reported, inferential, or wishful evidence for $p$.

\subsection{Results and discussion}

Due to the random sampling of items, we obtained between 3 and 14 strength ratings for each piece of evidence. We interpret the slider value between 0 ("impossible") and 1 ("absolutely certain") as a participant's estimate of the probability of $p$ given $e$, which we will also refer to as evidence strength. Strength of each piece of evidence in both the English and German task is shown in Fig. 1. We used these pieces of evidence in the design of Experiments 2 and 3; analyses employed evidence strength means (indicated by black dots in the Figure) and evidence type.

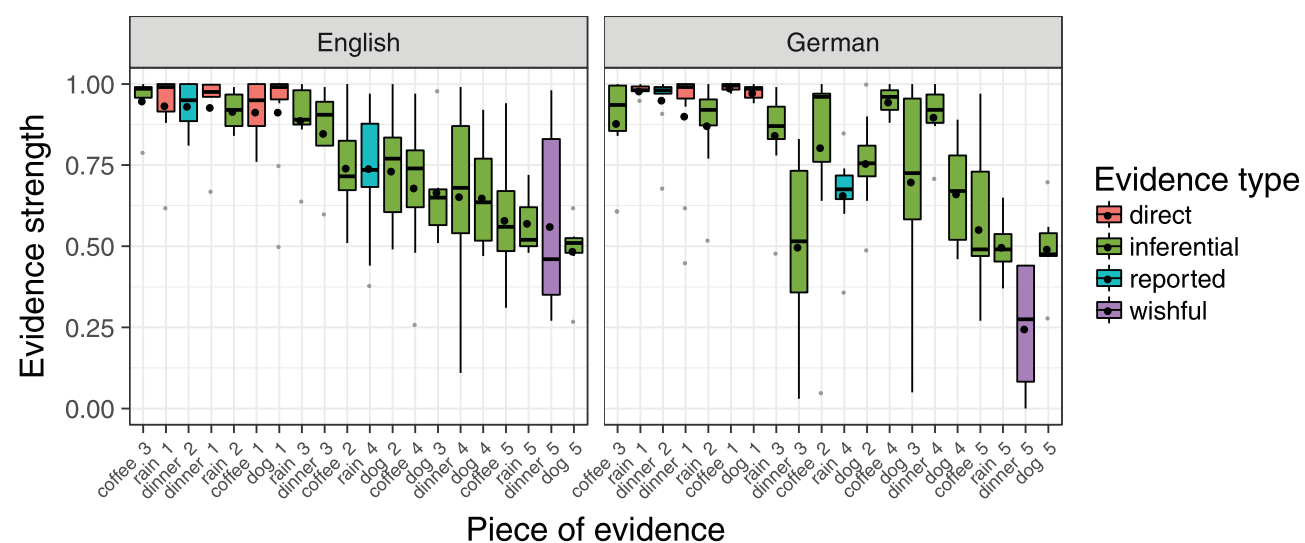

Fig. 1. Boxplots of by-item evidence strength for English (left) and German (right). Pieces of evidence occur in the same order in the English and German panels and are sorted by the English means. X-axis labels map onto item number in Appendix A. Horizontal lines indicate medians, dots indicate means. Color indicates evidence type. Boxes indicate the range into which $50 \%$ of the data fall. Whiskers extend to 1.5 times the interquartile range. (For interpretation of the references to color in this figure legend, the reader is referred to the Web version of this article).

To test whether the English and German distributions of strength ratings differed, and to test whether evidence strength is systematically predicted by evidence type, we conducted two mixed-effects linear regressions. Both predicted evidence strength rating from a dummy-coded fixed effect of language (with English as reference level) as well as by-participant and by-item random intercepts and by-item random slopes for language. Each regression further included a fixed effect of evidence type one according to the classification described above and one according to a reduced classification in which all types that were not

\footnotetext{
2 Pieces of evidence were generated through a separate English free production paradigm. A speaker's description of some state of affairs $p$ was given to participants and they were asked to provide a free response explanation of how the speaker knew about $p$. This experiment can be viewed here. Similar responses (e.g., "he can hear it" and "he can hear it on the roof") were grouped together. For the current experiment, we selected explanations from among those most frequently generated while attempting to include at least one example of each type of evidence (direct, reported, inferential). This procedure resulted in the final selection of five pieces of evidence per state of affairs. English materials were translated into German by authors 1 , 2, and 4, who are native speakers of German.
} 
direct were grouped into an "other" category. For both evidence type predictors, "direct" was the reference level. The effect of language did not reach significance in either regression $(\beta=-.01(-.01), S E=.03(.03), t=-.22(-.16), p<.83(.88)$; values in parentheses are from the reduced evidence type regression), suggesting that the two populations did not differ in their estimates of evidence strength. In addition, as suggested by Fig. 1, inferential evidence for $p$ was rated as weaker than direct evidence $(\beta=-.21, S E=.07, t=-3.16, p<.007)$, as was wishful evidence $(\beta=-.44, S E=.13, t=-3.43, p<.004)$. However, reported evidence was not rated as weaker than direct evidence $(\beta=-.09, S E=.1, t=-.92, p<.38)$. Similarly, in the reduced evidence type regression, other evidence was rated as weaker evidence for $p$ than direct evidence $(\beta=-.24, S E=.07, t=-2.81, p<.02)$.

The evidence type results are in line with the suggestions and intuitions from the literature. Nevertheless, two points are worth emphasizing. First, there was a substantial amount of variability in perceived evidence strength among the inferential pieces of evidence. Second, there was also variability in evidence type among the most strongly rated pieces of evidence. The five most strongly rated pieces of evidence for $p$ include direct, reported, and inferential evidence. For instance, the strongest three pieces of evidence were the following:

- Evidence for the coffee being cold: "You know that the coffee has been on the table for an hour." (inferential)

- Evidence for rain: "You look out the window and see raindrops falling from the sky." (direct)

- Evidence for dinner being ready: "Your spouse tells you that dinner is ready." (reported)

What this suggests is that evidence strength is a dimension of evidence that, while correlated with evidence type, is not captured fully by the direct/reported/inferential distinction. In the following experiments, we therefore include both evidence type and evidence strength in the analyses.

\section{Experiment 2: production}

The following experiment addressed the first main question of interest: under what evidential circumstances do speakers use which evidential devices? In other words, what are the evidential use conditions for the cross-linguistic devices we focus on? We thus investigate the interaction between speakers' choice of closely-related evidential expressions and concrete scenarios. To this end, we evaluated speakers' intuitions in a forced production task, testing how likely they are to use a particular evidential device to communicate their belief about $p$ when confronted with the pieces of evidence from Exp. 1, which differ in how strongly they support $p .^{3}$ The German version was identical with the exception that it was conducted in German and contained slightly different utterance choices (explained below). ${ }^{4}$

\subsection{Methods}

\subsubsection{Participants}

For the English version, we recruited 40 participants from Amazon's Mechanical Turk. For the German version, we recruited 40 participants on the German crowd-sourcing service Clickworker. Participants were compensated for their participation.

\subsubsection{Materials and procedure}

Participants were asked to choose one of four possible utterances to describe the situation to a friend. On each trial, they first saw a context sentence which varied by domain (e.g., "Imagine that you are sitting in a room"). Next, they were presented with a piece of evidence (e.g., "Earlier today, you saw dark clouds in the sky"). Finally, each participant saw the same question: "Given what you know, what do you say to a friend who is sitting in a windowless room down the hall?" They then chose one of four possible utterances by checking a radio button (e.g., "It's raining," "It must be raining," "It's probably raining," "It might be raining"). Depending on the language of testing, possible utterances took the forms shown in (12) or (13); for German we included the bare $p$ form and must $p$ as in the English version, but instead of the modals probably and might, we included the modal adverbial vermutlich ('probably') and the discourse particle wohl. This design allows us to compare not only certain types of modals to the epistemic use of must (and to statements with no evidential markers at all), but also to compare both modals and must to discourse particles.

(12) Form of English utterance choices:

a. $p$ (bare)

b. must $p$ (must)

c. probably $p$ (probably)

d. might $p$ (might)

\footnotetext{
${ }^{3}$ The English version of this experiment can be viewed here.

${ }^{4}$ The German version of this experiment can be viewed here.
} 
(13) Form of German utterance choices:

a. $p$ (bare)

b. muss $p$ (muss)

c. wohl $p$ (wohl)

d. vermutlich $p$ (vermutlich)

Each participant completed 12 trials, three per domain. For each participant and domain, three pieces of evidence were randomly sampled from the set of five. Trial order was randomized, as was the order of utterance options.

\subsection{Results and discussion}

The overall distribution of utterance choices is shown in Fig. 2. In both English and German, the bare form is used most frequently. In English, might is also used frequently, with both must and probably being chosen at only half the rate. A similar picture obtains in German, where muss $p$ is generally dispreferred.
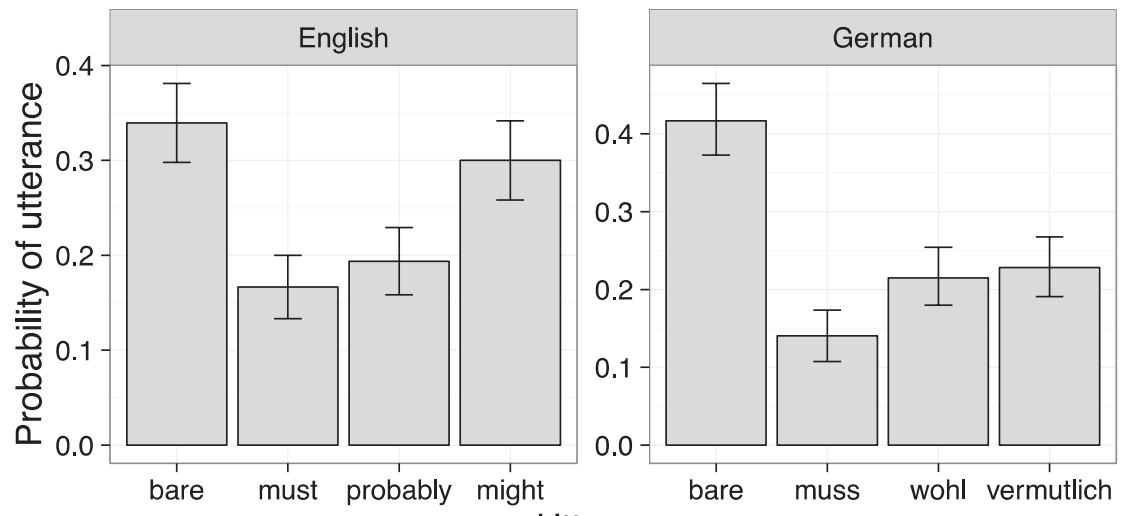

Utterance

Fig. 2. Probability of utterance choice for English (left) and German (right). Error bars indicate bootstrapped $95 \%$ confidence intervals.

The main question of interest is whether the choice of form to communicate about $p$ depends on the strength and type of the evidence for $p$. Indeed, it does: Fig. 3 shows the proportion of utterances chosen as a function of evidence strength, and Fig. 4 shows the proportion of utterances chosen as a function of evidence type. In order to evaluate the effect of evidence strength and evidence type on utterance choice, we conducted two series of logistic mixed effects models - one for the English data, one for the German data - predicting utterance choice from two evidence predictors. One was a centered predictor for evidence strength. The other predictor encoded direct vs. all other evidence types (the distinction assumed by von Fintel and Gillies (2010) to matter especially for the choice of must) and was subsequently centered. Each series contained four models, one each for each of the four possible utterances. Each model contained the maximal random effects structure that allowed the models to converge (by-participant and by-item random intercepts). The results are summarized in Table 1.
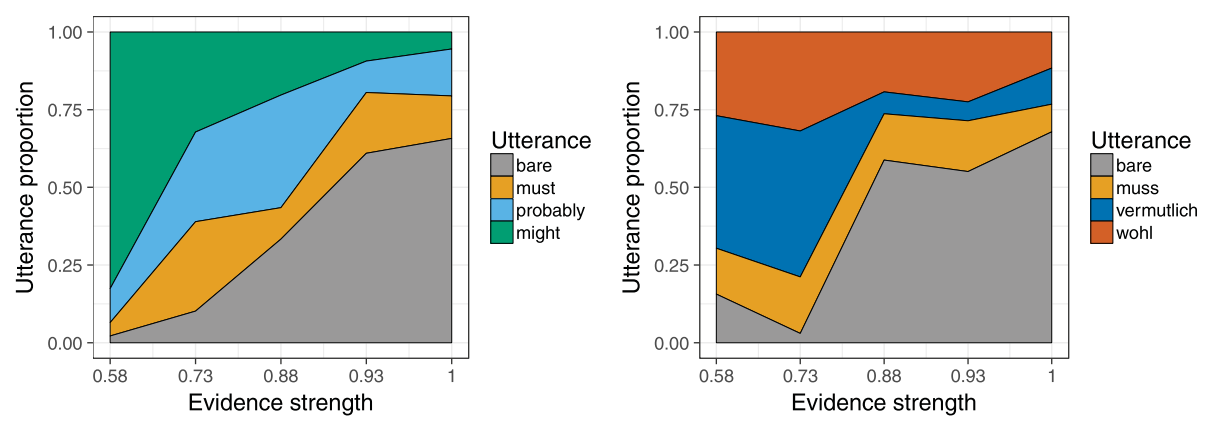

Fig. 3. Proportion of utterance choice as a function of evidence strength for English (left) and German (right). X-axis labels indicate the maximum evidence strength for the bin that the utterance proportion was computed over. 

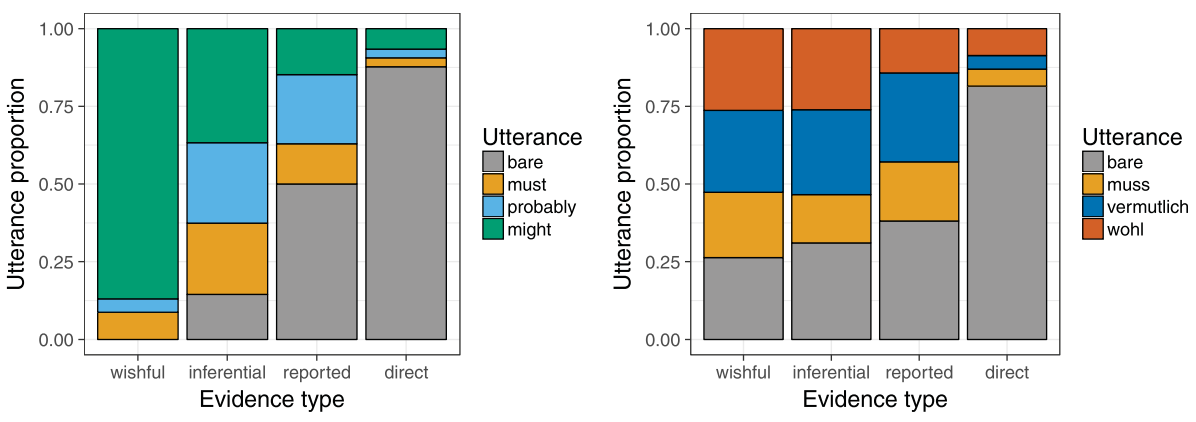

Fig. 4. Proportion of utterance choice as a function of evidence type for English (left) and German (right).

In both English and German, both evidence strength and evidence type affected the choice of the bare form: the bare form is more likely to be chosen with stronger evidence, and with direct evidence. The choice of $\mathrm{must} / \mathrm{muss}$ significantly depended on both evidence strength and evidence type in English, but only on evidence type in German: in both languages, must/muss was less likely with direct evidence. Additionally, in English, stronger evidence resulted in a greater log odds of choosing must. English probably was less likely to be used with direct evidence, but the effect of evidence strength did not reach significance. English might, in contrast, was less likely to be used with stronger evidence, but the effect of evidence type did not reach significance. A similar asymmetry in the effects of evidence type and strength obtained in the German data: German vermutlich was less likely to be used with stronger evidence, but the effect of evidence type did not reach significance. In contrast, German wohl was less likely to be used with direct evidence, but the effect of evidence strength did not reach significance.

Table 1

Model results for the English (left) and German (right) series of mixed effects logistic regressions.

\begin{tabular}{|c|c|c|c|c|c|c|c|}
\hline \multirow[t]{2}{*}{ Expression } & \multirow[t]{2}{*}{ Predictor } & \multicolumn{3}{|l|}{ English } & \multicolumn{3}{|c|}{ German } \\
\hline & & Coef $\beta$ & $\mathrm{SE}(\beta)$ & $p$ & Coef $\beta$ & $\mathrm{SE}(\beta)$ & $p$ \\
\hline \multirow[t]{3}{*}{ Bare } & Intercept & -1.64 & 0.48 & $<.001$ & -0.53 & 0.30 & $<.09$ \\
\hline & Evidence strength & 10.75 & 3.61 & $<.01$ & 3.93 & 1.60 & $<.05$ \\
\hline & Evidence direct & 3.05 & 1.18 & $<.01$ & 1.83 & 0.81 & $<.05$ \\
\hline \multirow[t]{3}{*}{ Must/muss } & Intercept & -2.21 & 0.30 & $<.0001$ & -2.04 & 0.22 & $<.0001$ \\
\hline & Evidence strength & 4.36 & 1.98 & $<.05$ & 0.39 & 0.85 & $<.66$ \\
\hline & Evidence direct & -3.01 & 0.88 & $<.001$ & -1.39 & 0.56 & $<.05$ \\
\hline \multirow[t]{3}{*}{ Probably } & Intercept & -1.98 & 0.31 & $<.0001$ & & & \\
\hline & Evidence strength & 2.27 & 2.15 & $<.3$ & & & \\
\hline & Evidence direct & -2.97 & 0.97 & $<.01$ & & & \\
\hline \multirow[t]{3}{*}{ Might } & Intercept & -1.41 & 0.30 & $<.0001$ & & & \\
\hline & Evidence strength & -12.29 & 2.24 & $<.0001$ & & & \\
\hline & Evidence direct & 0.25 & 0.83 & $<.78$ & & & \\
\hline \multirow[t]{3}{*}{ Vermutlich } & Intercept & & & & -1.70 & 0.27 & $<.0001$ \\
\hline & Evidence strength & & & & -3.61 & 1.29 & $<.01$ \\
\hline & Evidence direct & & & & -1.19 & 0.80 & $<.15$ \\
\hline \multirow[t]{3}{*}{ Wohl } & Intercept & & & & -1.45 & 0.16 & $<.0001$ \\
\hline & Evidence strength & & & & -0.82 & 0.70 & $<.25$ \\
\hline & Evidence direct & & & & -1.06 & 0.45 & $<.05$ \\
\hline
\end{tabular}

p-values lower than .05 are bolded.

\subsection{Discussion}

While there was a clear effect of evidence type on the choice of must/muss, in line with the claims of von Fintel and Gillies (2010), there are two things worth noting: first, that this effect was not absolute. That is, in both English and German, must/ muss was sometimes chosen even when the evidence provided was direct. ${ }^{5}$ Second, the additional effect of evidence strength above and beyond evidence type in English suggests that theories of evidential devices should take into account not just type, but strength of evidence as well, even though, as shown in Experiment 1, the two are correlated. The fact that German vermutlich was less likely to be used with stronger evidence and that the effect of evidence strength did not reach significance in the case of German wohl points to a potentially interesting difference between these quasi-synonymous modal devices that has not been investigated in the semantics literature at all.

\footnotetext{
${ }^{5}$ One might be tempted to attribute these choices to performance errors. However, we believe this interpretation is highly unlikely given that the experiment was very short ( 12 trials) and therefore unlikely to induce tiredness in participants. Alternatively, one might want to argue that the choices are the result of presupposition accommodation, where direct evidence is reinterpreted as indirect evidence via distrust in one's own senses. We cannot rule out this possibility.
} 
In sum, we interpret our results as follows. First, bare utterances result from very strong evidence: when certainty of $p$ is very high, the claim that $p$ may be made directly. As evidence strength decreases, speakers employ evidential devices that track evidence strength. In German, due to the lexical inventory of discourse particles, speakers have a choice of using epistemic adverbs such as vermutlich, epistemic muss, and particles like wohl. As Fig. 3 shows, speakers tend to use muss and wohl instead of the respective adverb when the degree of evidence strength is higher. In other words, when investigating the dependence on evidence strength for $p$, we find that muss and wohl pattern together, in contrast to other modal means such as vermutlich. This is an interesting result given what we have discussed in Section 1.2 above, since our results suggest a useconditional difference between discourse particles and otherwise synonymous adverbs in the domain of speaker commitment that has not been observed in the theoretical literature and that is due to use conditions (i.e., in which evidential environments to use these devices) rather than to fundamental semantic differences. On the other hand, we see that epistemic müssen patterns with wohl with regard to felicitous evidential environments, and this parallel again indicates similar use restrictions rather than semantic differences and/or similarities between modal expressions and discourse particles that are discussed in the literature.

\section{Experiment 3a: comprehension (listener belief)}

We next tested the flip side of the communicative coin: What are the inferences that listeners draw when observing the various evidential devices explored in Experiment 2? In particular, depending on the utterance $u$ used to communicate about $p$, (i) how strong are listeners' resulting beliefs in $p$; (ii) what do they take the speaker to be committed to in uttering $u$; and (iii) what do they believe to be the type and strength of evidence for $p$ that the speaker was in possession of when producing $u$ ? Experiment 3a addresses questions (i) and (iii) and Experiment 3b addresses questions (ii) and (iii). We first report Experiment 3a. ${ }^{6}$ The English and German experiments were identical except for the language of testing and the target utterances presented to participants: English participants saw the set in (12), German participants the one in (13).

\subsection{Methods}

\subsubsection{Participants}

For the English version, we recruited 60 participants through Amazon's Mechanical Turk. For the German version, we recruited 60 participants through the German crowd-sourcing service Clickworker. Participants were compensated for their participation.

\subsubsection{Materials and procedure}

Participants were presented with an utterance $u$ (e.g., "It must be raining") and asked to both rate the probability of the state of affairs $p$ obtaining (e.g., it is raining) and to select one out of five pieces of evidence that the speaker most likely had about $p$ in choosing the utterance. On each trial, participants first saw two context sentences: "You are in a windowless room. Your friend X walks in and says: [ ...]," where "X" was a randomly generated name. ${ }^{7}$ Participants then saw one of the utterances from Experiment 2 that "X" produced (e.g., "It must be raining"). They were then asked about the strength of their belief in $p$ : "How likely do you think it is that it is raining?" and adjusted a slider with endpoints labeled "impossible" (coded as 0 ) and "certain" (coded as 1 ). Once they indicated their belief in $p$, the five potential pieces of evidence previously used in Experiments 1 and 2 were shown and participants were asked to choose the one the speaker likely had: "How do you think X knows about the rain?"

Participants provided one set of judgments for each domain, resulting in four trials per participant. Each participant saw each type of utterance (English: bare, must, probably, might; German: bare, muss, wohl, vermutlich) across trials. Utterance types were randomly distributed across domains. Trial order was randomized, as was the order in which pieces of evidence were displayed.

\subsection{Results and discussion}

Two questions are of interest: first, does the probability of listener belief in $p$ vary as a function of the observed utterance? In other words, how are listeners' beliefs influenced by various evidential devices? Second, does the type and strength of the evidence for $p$ inferred to be available to the speaker vary as a function of the observed utterance? To address the first question, we conducted a mixed effects linear regression predicting degree of belief in $p$ from a dummy-coded utterance predictor with must/muss as the reference level, separately for English and German. The model included random byparticipant and by-item intercepts. Fig. 5 (white bars) shows mean probability of listener belief in $p$ by utterance: participants believed $p$ was more likely after observing the bare utterance than after observing the must utterance in English $(\beta=.24, S E=.03, t=9.1, p<.0001)$ and the muss utterance in German $(\beta=.22, S E=.03, t=7.5, p<.0001)$. In contrast, in

\footnotetext{
${ }^{6}$ The English version of this experiment can be viewed here and the German version here.

7 The naming of speakers was done to discourage effects of inferences about speaker-specific language use on interpretation.
} 
English they believed $p$ was less likely after observing might $p(\beta=-.09, S E=.03, t=-3.44, p<.0008)$. There was no difference in resulting listener belief between must $p$ and probably $p(\beta=-.04, S E=.03, t=-1.6, p<.12)$. And in German, there were no differences in degree of belief in $p$ between muss $p$ and vermutlich $p(\beta=-.02, S E=.03, t=-.76, p<.46)$, nor between muss $p$ and wohl $p(\beta=.01, S E=.03, t=.43, p<.67)$.

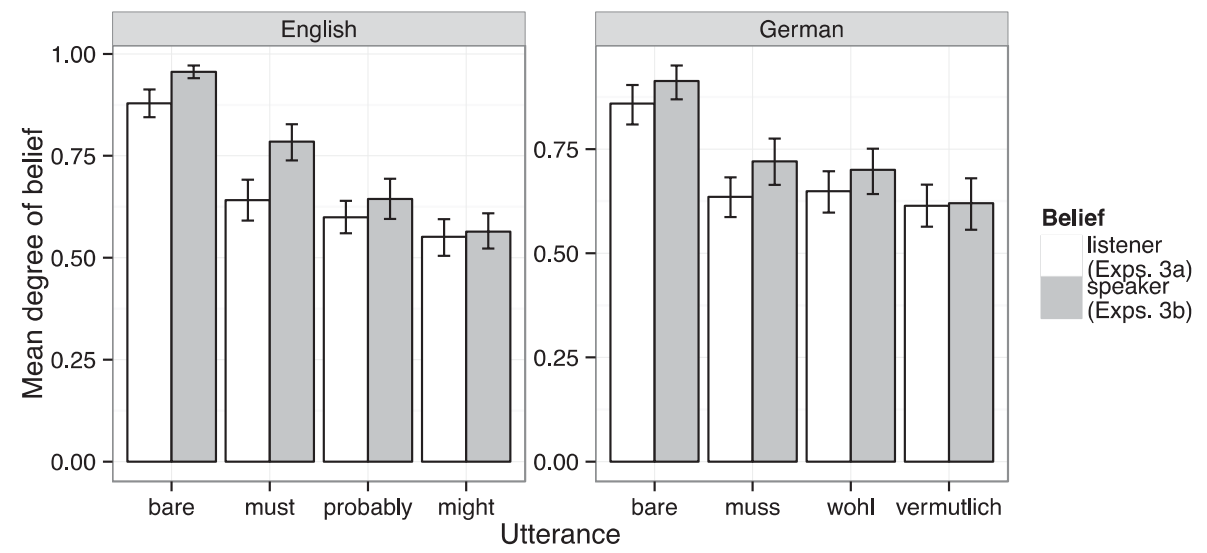

Fig. 5. Mean probability of listener and speaker belief in p by utterance for English (left) and German (right). Error bars indicate 95\% bootstrapped confidence intervals.

To address the question of whether inferred speaker evidence tracks the production results reported in Section 3, we conducted two further mixed effects regressions: a linear model predicting inferred strength of evidence for $p$, and a logistic model predicting log odds of the speaker having had direct vs. any other type of evidence. The models included a dummycoded utterance predictor with must/muss as reference level, separately for English and German. The models included the maximal random effects structure that allowed the models to converge (random by-participant and by-item intercepts). Figs. 6 and 7 in Section 5 below show mean evidence strength and type, respectively, that was ascribed to speakers depending on the utterance they chose. In English, participants inferred stronger evidence was available to the speaker after observing the bare utterance than must $p(\beta=.08, S E=.02, t=3.74, p<.0003)$ and the evidence was more likely to be $\operatorname{direct}(\beta=3.36$, $S E=.78, p<.0001)$, but inferred evidence strength was no different for probably $p(\beta=.01, S E=.02, t=.55, p<.59)$ or might $p$ $(\beta=-.02, S E=.02, t=-.89, p<.38)$, nor was inferred evidence type $(\beta=.28, S E=.81, p<.73$ and $\beta=.13, S E=.81, p<.73)$. Similarly in German, participants inferred stronger evidence was available to the speaker after observing the bare utterance than muss $p(\beta=.08, S E=.02, t=3.23, p<.002)$ and the evidence was more likely to be $\operatorname{direct}(\beta=3.40, S E=.86, p<.0001)$. In addition, they inferred that the available evidence must have been weaker upon observing vermutlich $p(\beta=-.05, S E=.02$, $t=-2.1, p<.04)$, but inferred evidence strength was no different for wohl $p(\beta=.001, S E=.02, t=.07, p<.95)$, nor was inferred evidence type $(\beta=.95, S E=.88, p<.29)$.

Taken together, the results of the current experiment on comprehension mirror those from production: bare utterances lead to the greatest degree of belief in $p$ while indicating that the speaker had access to very strong and likely direct evidence. Listener belief and inferred evidence strength decrease with the epistemic modals; must/muss patterns with probably/vermutlich. Crucially, muss also patterns with the discourse particle wohl. We observed the same similarity in behavior between muss and wohl in the context of production in Experiment 2. In Section 6 below, we return to these effects (in both comprehension and production) in more detail.

\section{Experiment 3b: comprehension (speaker commitment)}

Experiment 3a tested listener belief in $p$ as a function of the observed utterance. A related dimension is the commitment to the truth of $p$ that listeners ascribe to speakers. For example, a particular utterance may lead the listener to infer that the speaker is highly committed to (i.e., holds a strong belief in) $p$, while nevertheless not instilling the same degree of belief in $p$ in the listener. In fact, epistemic must has been claimed to function like this: von Fintel and Gillies (2010) claim that maximal speaker commitment is necessary for the use of epistemic must, just as in the use of the bare form; yet in comprehension the interpretation of must $p$ is weaker than that of bare $p$. That is, after hearing must $p$, listeners form beliefs in $p$ that are weaker than what they take to be speakers' beliefs in $p$. Experiment $3 \mathrm{~b}$ thus tested the degree of belief in $p$ that listeners ascribe to speakers depending on the utterance the speaker produced. ${ }^{8}$

\footnotetext{
8 This experiment can be viewed here. The German version can be viewed here.
} 


\subsection{Methods}

\subsubsection{Participants}

We recruited 60 English native speakers through Amazon's Mechanical Turk, and 60 German native speakers through Clickworker. Participants were compensated for their participation.

\subsubsection{Materials and procedure}

The design, procedure, and materials were identical to those of Experiment 3a with the exception of the dependent measure: instead of asking participants about their own strength of beliefs in $p$, they instead evaluated the speaker's belief in $p$ : "Does X think that it's raining?" Participants indicated their response by adjusting a slider on a scale with endpoints labeled "Definitely not" (coded as 0 ) and "Definitely" (coded as 1 ).

\subsection{Results and discussion}

As in Experiment 3a, two questions are of interest: first, does the probability of belief in $p$ - this time, as ascribed to the speaker rather than the listener's own belief - vary as a function of the observed utterance? Second, does the type and strength of the evidence for $p$ inferred to be available to the speaker vary as a function of the observed utterance?

To address the first question, we conducted a mixed effects linear regression predicting degree of belief in $p$ from a dummy-coded utterance predictor with must/muss as reference level, separately for English and German. The model included random by-participant and by-item intercepts. Fig. 5 (gray bars) shows mean probability of ascribed speaker belief in $p$ by utterance: participants believed the speaker was more likely to believe $p$ after observing the bare utterance than after observing the must utterance in English $(\beta=.18, S E=.03, t=6.59, p<.0001)$ or the corresponding muss utterance in German $(\beta=.19, S E=.03, t=5.79, p<.0001)$. In contrast, they believed the speaker was less likely to believe $p$ if they produced probably $p(\beta=-.14, S E=.03, t=-5.28, p<.0001)$ or might $p(\beta=-.22, S E=.03, t=-8.36$, $p<.0001)$. In German, participants believed the speaker was less likely to believe $p$ if they produced vermutlich $p(\beta=-.1$, $S E=.03, t=-3.01, p<.004)$; there was no difference between muss $p$ and wohl $p(\beta=-.02, S E=.03, t=-.61, p<.55)$. This shows, similar to what we found in the domain of production, that perceived speaker commitment in the case of both epistemic must and discourse particles is stronger than in the case of using otherwise synonymous adverbs such as vermutlich.

These results mirror the effects found in Experiment 3a, with the exception that all utterances led to differences in ascribed speaker commitment. Interestingly, the strength of the belief that participants attributed to speakers was stronger than their own resulting belief. This was borne out statistically in a model that was applied to both the listener and speaker belief datasets. This model was identical to that just reported, but additionally allowed for a dummy-coded belief holder predictor (listener vs. speaker) to interact with utterance. There was a clear main effect of belief holder, such that the belief ascribed to speakers was stronger than that held by listener participants, both in English $(\beta=.14, S E=.03$, $t=4.7, p<.0001)$ and in German $(\beta=.08, S E=.04, t=2.23, p<.03)$. Note that this finding suggests that must is not special in generating the effect of stronger speaker commitment than resulting listener belief; all utterances are similarly affected.

As in Experiment 3a, to address whether inferred speaker evidence strength and type mirrors production, we conducted two further mixed effects regressions, one linear (predicting inferred strength of evidence for $p$ ) and one logistic (predicting whether evidence type was direct) from a dummy-coded utterance predictor with must/muss as reference level. The model included random by-participant and by-item intercepts. Fig. 6 shows mean evidence strength ascribed to speakers by utterance and Fig. 7 shows the distribution of inferred evidence types by utterance: again, participants inferred stronger evidence was available to the speaker after observing the bare utterance than must/muss $p$ in both English $(\beta=.06, S E=.02, t=3.2, p<.002)$ and German $(\beta=.08, S E=.02, t=4.05, p<.0001)$, and that the evidence was more likely to be direct (English: $\beta=4.69, S E=1.05, p<.0001$, German: $\beta=2.19, S E=.59, p<.0001$ ), However, inferred evidence strength was no different in English for probably $p(\beta=-.02, S E=.02, t=-1.11, p<.27)$ or might $p(\beta=-.01$, $S E=.02, t=-.49, p<.63$ ) and neither was inferred evidence type (probably: $\beta=3.36, S E=.78, p<.0001 ;$ might: $\beta=3.36, S E=.78, p<.0001$ ); the same was true in German for vermutlich $p$ (strength: $\beta=-.0003, S E=.02, t=-.02$, $p<.99$, type: $\beta=-.26, S E=.71, p<.71$ ) or wohl $p$ (strength: $\beta=.008, S E=.02, t=.36, p<.72$, type: $\beta=-.19, S E=.71$, $p<.79)$.

Allowing this model to interact with a belief holder predictor and applying it simultaneously to the Experiment 3a dataset yields no main effect of belief holder in either English $(\beta=.03, S E=.02, t=1.53, p<.13)$ or German $(\beta=.0008, S E=.03$, $t=.04, p<.97)$. This finding is unsurprising and serves as a sanity check for the belief holder effect, given that this aspect of the dependent measure was identical across experiments. 


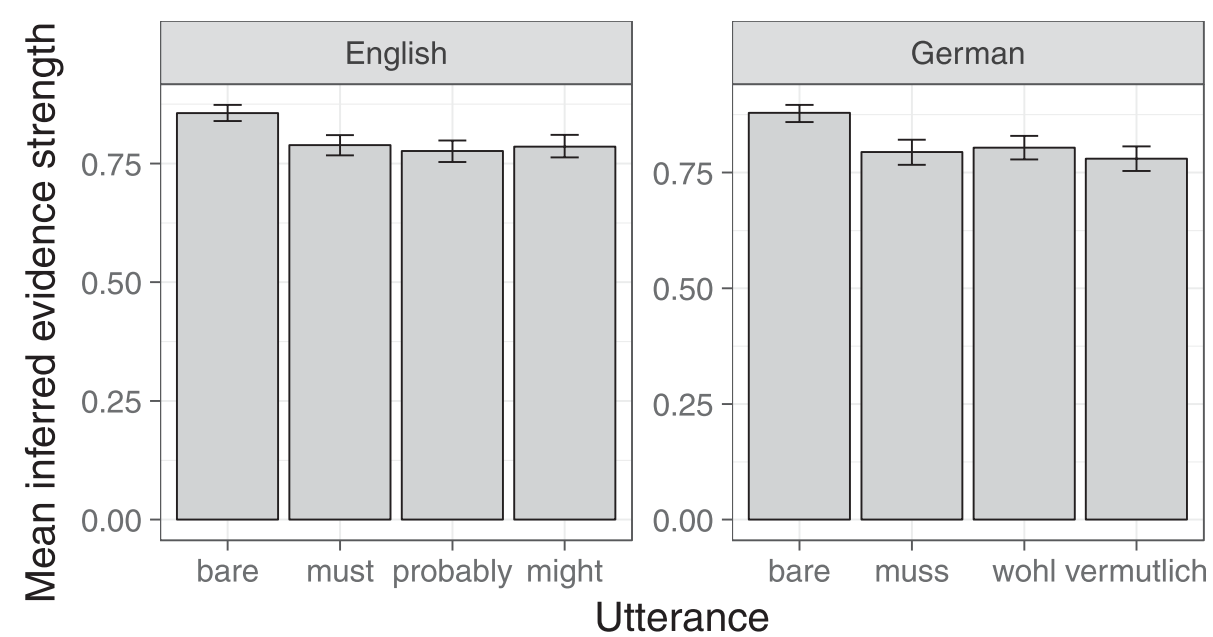

Fig. 6. Mean inferred evidence strength by utterance for English (left) and German (right). Error bars indicate 95\% bootstrapped confidence intervals (data pooled across Exps 3a and 3b).

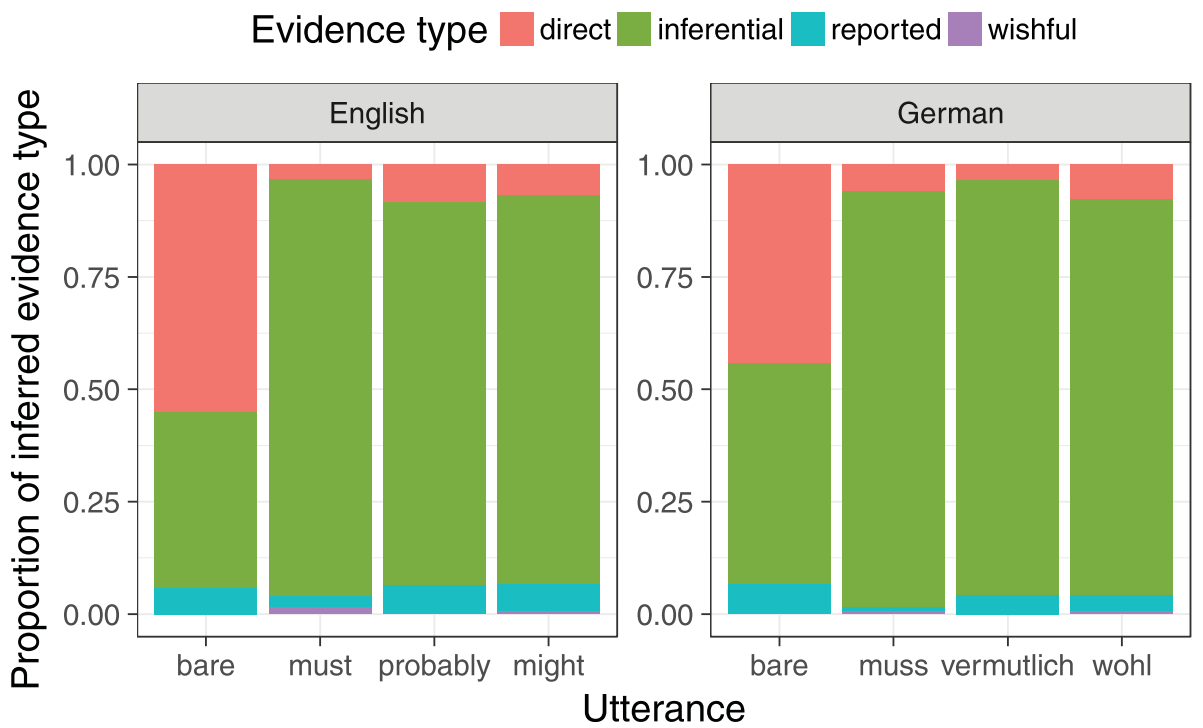

Fig. 7. Proportion of inferred evidence type by utterance for English (left) and German (right, data pooled across both Exps 3a and 3b).

\section{Conclusions and outlook}

In this paper, we presented a series of experiments focusing on the extent to which listeners' interpretation of certain types of evidential devices and their judgments about speaker commitment differ in strength. We demonstrated that speakers' production preferences for these different devices mirror the comprehension results under varying evidential circumstances. By investigating the use of evidential devices from this perspective, we introduced a new experimental paradigm for exploring the impact of different evidential circumstances on the use of modal evidentials, epistemic discourse particles, and statements with no evidential markers at all. In other words, we introduced an experimental paradigm for mapping the empirical terrain of evidential devices.

Although our experimental data cannot decide between the various theoretical accounts on challenging phenomena such as epistemic must (Section 1.1) and discourse particles (Section 1.2), a complete picture of these evidential means of natural languages requires systematically testing the compatibility of these devices with different degrees of evidence strength and evidential circumstances; we have presented an experimental paradigm for doing just that. This paradigm will allow for the exploration of how different evidential devices are used and comprehended compared to alternative lexical choices. It also highlights the role of speaker commitment in theories of evidential devices. Below, we comment on some of the conclusions we can draw from our results.

As for discourse particles, no study has to date taken into account the component of different degrees of speaker commitment when debating how, for instance, closely related sentence adverbs can be distinguished from synonymous 
discourse particles at the level of semantics. This is a new data point that needs to be accounted for in our theoretical understanding of the lexical inventory of evidential words in the German language.

As for epistemic must, we could, as expected, confirm the claim that the epistemic use of must expresses a weaker commitment than the bare form. However, in addition to experimentally confirming this (admittedly) trivial observation, we have tested for different degrees of evidence strength and also compared epistemic must not only to the bare form but also to alternative modal expressions available in the English lexicon (i.e., adverbs and might). In this context, we found that must is used in evidential circumstances where speaker commitment can be considered rather strong. This appears to concur with claims in the literature that highlight this strong component of must (e.g., von Fintel and Gillies, 2010, 2016). However, the results also suggested that speaker commitment is lower for must than for the bare form. This is at odds with von Fintel \& Gillies' claim that "[s]peakers who say must $\Phi$ are just as strongly committed to the prejacent as those who assert $\Phi$ by itself" (von Fintel and Gillies, 2010: 30). ${ }^{9}$ This result might also serve to explain concrete felicity effects in the lexical domain of modal expressions as recently described by Matthewson and Truckenbrodt (2017). They point out that epistemic must/muss stands in sharp contrast to the epistemic use of other modals such as sollen in German. In particular, must/muss is considerably stronger in the domain of speaker commitment. Consider one of their German examples (Matthewson and Truckenbrodt, 2017: 12):

(14) [Heike says that Maria is in the kitchen, but I am not convinced, since I think I would have seen her go into the kitchen. I say:]

a. \# Maria muss in der Küche sein (aber ich habe meine Zweifel).

Maria must in the kitchen be (but I have my doubts) 'Maria must be in the kitchen (but I have my doubts).

b. Maria soll in der Küche sein (aber ich habe meine Zweifel). Maria SOLL in the kitchen be (but I have my doubts)

'Maria is supposed to be in the kitchen (but I have my doubts).'

The context in (14) provides a report in the context, and epistemic muss, in contrast to sollen, requires a strong commitment to the prejacent and can thus not be used in a context where the speaker might have doubts to a certain extent. We hypothesize that both probably and might (our tested items) pattern with soll rather than with muss/must, meaning that muss/must conveys a rather high degree of speaker commitment, and this is what we found in our experiments.

All in all, given that the theoretical literature on English and German evidential words is often based on subtle judgments of utterances, our paper presents for the first time an experimental investigation on cross-linguistic expressions conveying different strengths of speaker commitment. Our new experimental paradigm thus illustrates a new approach that focuses on differences and similarities in the use conditions of the lexical inventory of evidentials across languages. In doing so, we provide a starting point for adding a use-oriented view to theoretical debates on the nature of evidential expressions and highlight the importance of an experimentally-driven perspective in this context.

\section{Acknowledgments}

We thank Justine Kao for her involvement in the earliest stages of this project, including experiment design, coding, and helpful discussion. We also thank Dan Lassiter, Chris Cummins, and the anonymous reviewers for helpful comments. This work was partially supported by the German Research Foundation (DFG grant TR 1228/2-1).

\section{A Pieces of evidence}

This section lists, for each proposition $p$, the five pieces of evidence that were used throughout all experiments.

\section{A.1 It's raining./Es hat geregnet}

1. You look out the window and see raindrops falling from the sky.

Sie sehen aus dem Fenster und beobachten, wie Regentropfen vom Himmel fallen.

Evidence type (full): perceptual

Evidence type (reduced): direct

\footnotetext{
${ }^{9}$ While a detailed analysis of the various pragmatic factors that might account for the weakness of must is outside the scope of this paper, we would like to acknowledge one way to derive this weakness via a Gricean Manner implicature, as previously proposed and computationally fleshed out within the Rational Speech Act framework by Degen et al. (2015): listeners explain away the speaker's use of the longer and hence costlier must form (instead of the shorter and less costly bare form) by inferring that the speaker must have been communicating something in addition to $p$ - for example, that the speaker is more weakly committed to $p$ than would be necessary for the use of the bare form.

${ }^{10}$ A reviewer suggested that this item as well as A.2.2 (cold coffee cup) might better be categorized as direct evidence because it counts as perceptual. However, what is at issue is not whether the evidence is perceptual in nature, but whether it serves as direct evidence for $p$ (that it is raining; or that the coffee is cold). If we do categorize these items as direct, we further increase both the proportion of uses of must $p$ with direct evidence as well as the probability of directness inferences in listeners who observe must $p$. Qualitatively, the statistical results remain unchanged, with the following exceptions: in production, the effect of evidence strength on English must changes from significant to marginal (without changing sign) and the effect of evidence directness for German vermutlich changes from non-significant to significant (without changing sign).
} 
2. You hear the sound of water dripping on the roof.

Sie können hören, wie Wasser auf das Dach prasselt.

Evidence type (full): inferential

Evidence type (reduced): indirect ${ }^{10}$

3. You check the weather report on the Internet, which says it is raining

Sie haben im Internet den Wetterbericht gelesen, in dem stand, dass es regnen würde.

Evidence type (full): reported

Evidence type (reduced): indirect

4. You see a person come in from outside with wet hair and wet clothes.

Sie sehen, wie jemand mit nassen Haaren und durchnässten Kleidern von draußen hereinkommt.

Evidence type (full): inferential

Evidence type (reduced): indirect

5. Earlier today, you had seen dark clouds in the sky.

Sie haben heute Vormittag dunkle Wolken am Himmel gesehen.

Evidence type (full): inferential

Evidence type (reduced): indirect

\section{A.2 The coffee is cold./Der Kaffee ist kalt geworden}

1. You take a sip of the coffee and feel that it is cold.

Sie trinken einen Schluck Kaffee und stellen fest, dass er kalt ist.

Evidence type (full): perceptual

Evidence type (reduced): direct

2. You touch the coffee cup and feel that it is cold.

Sie berühren die Kaffeetasse und stellen fest, dass sie kalt ist.

Evidence type (full): inferential

Evidence type (reduced): indirect

3. You see that there is no steam coming from the coffee.

Sie sehen, dass aus dem Kaffee kein Dampf aufsteigt.

Evidence type (full): inferential

Evidence type (reduced): indirect

4. You know that the coffee has been on the table for an hour.

Sie wissen, dass der Kaffee seit einer Stunde auf dem Tisch steht.

Evidence type (full): inferential

Evidence type (reduced): indirect

5. You see that the cup isn't insulated.

Sie sehen, dass die Tasse nicht isoliert ist.

Evidence type (full): inferential

Evidence type (reduced): indirect

\section{A.3 Dinner is ready./Das Abendessen ist fertig geworden}

1. You just prepared dinner and set it out on the table.

Sie haben gerade das Abendessen zubereitet und auf den Tisch gestellt.

Evidence type (full): perceptual

Evidence type (reduced): direct

2. Your spouse tells you that dinner is ready.

Ihr/e Partner/in sagt, dass das Abendessen fertig ist.

Evidence type (full): reported

Evidence type (reduced): indirect

3. Dinner is usually ready at around $6 \mathrm{pm}$. You look at the clock and it is $6 \mathrm{pm}$.

Sie wissen, dass das Abendessen normalerweise um $18 \mathrm{Uhr}$ fertig ist. Ein Blick auf die Uhr zeigt, dass es gerade $18 \mathrm{Uhr}$ ist.

Evidence type (full): inferential

Evidence type (reduced): indirect

4. You smell food coming from the dining room.

Sie vernehmen den Geruch von Essen, der aus dem Esszimmer kommt.

Evidence type (full): inferential

Evidence type (reduced): indirect

5. You're hungry.

Sie haben Hunger

Evidence type (full): wishful

Evidence type (reduced): indirect 


\section{A.4 The neighbor's dog is barking./Der Nachbarshund hat gebellt}

1. You look outside and see Fluffy, the neighbor's dog, standing on the porch and barking

Sie schauen aus dem Fenster und sehen Struppi, den Hund der Nachbarn, wie er am Zaun steht und bellt.

Evidence type (full): perceptual

Evidence type (reduced): direct

2. You hear the sound of a dog barking.

Sie hören einen Hund bellen.

Evidence type (full): inferential

Evidence type (reduced): indirect

3. You are listening to music with your earphones. You know that your neighbor's dog often barks in the evening.

Sie haben Kopfhörer auf und hören Musik, wissen aber, dass der Hund der Nachbarn abends oft bellt.

Evidence type (full): inferential

Evidence type (reduced): indirect

4. You are listening to music with your earphones. You look out the window and see that the mailman has just arrived at your neighbor's doorstep, when all of a sudden he jumps back.

Sie haben Kopfhörer auf und hören Musik, sehen aber aus dem Fenster und beobachten, wie der Postbote vor der Nachbarstür einen Satz nach hinten macht.

Evidence type (full): inferential

Evidence type (reduced): indirect

5. Your neighbor just got a new dog.

Sie wissen, dass sich die Nachbarn gerade einen Hund angeschafft haben.

Evidence type (full): inferential

Evidence type (reduced): indirect

\section{References}

Aikhenvald, A.Y., 2004. Evidentiality, Oxford University Press, Oxford.

Aikhenvald, A.Y., 2014. The grammar of knowledge: a cross-linguistic view of evidentials and the expression of information source. In: Aikhenvald, A.Y., Dixon, R.M.W. (Eds.), The Grammar of Knowledge: a Cross-Linguistic Typology. Oxford University Press, Oxford, pp. 1-51.

Cardinaletti, A., 2011. German and Italian modal particles and clause structure. Ling. Rev. 28, 493-531.

Degen, J., Kao, J., Scontras, G., Goodman, N.D., 2015. A cost and information-theoretic account of epistemic "must”. In: Poster Presented at CUNY 2015, Los Angeles, Mar 19-21.

Döring, S., Repp, S., 2016. The modal particles ja and doch and their interaction with discourse structure: corpus and experimental evidence. To appear. In: Featherston, S., Hörnig, R., von Wietersheim, S., Winkler, S. (Eds.), Information Structure and Semantic Processing. de Gruyter, Berlin.

Dörre, L., Trotzke, A., 2017. The processing of secondary meaning: an experimental comparison of focus and modal particles in wh-questions. To appear. In: Gutzmann, D., Turgay, K. (Eds.), Secondary Meaning and Linguistic Encoding. Brill, Leiden.

Ernst, T., 2007. On the role of semantics in a theory of adverb syntax. Lingua 117, 1008-1033.

Giannakidou, A., Mari, A., 2016. Epistemic future and epistemic MUST: nonveridicality, evidence, and partial knowledge. In: Blaszczak, J., Giannakidou, A., KlimekJankowska, D., Migdalski, K. (Eds.), Mood, Aspect, Modality Revisited: New Answers to Old Questions. The University of Chicago Press, Chicago, pp. 75-124. Goodhue, D., 2016. Epistemic must is not evidential, it's epistemic. Proceeding of NELS 46, 321-334.

Grosz, P., 2016. Discourse particles. To appear. In: Matthewson, L., Meier, C., Rullmann, H., Zimmermann, T.E. (Eds.), The Companion to Semantics (SemCom). Wiley, Oxford.

Grosz, P., 2017. Shedding new light on the wohl muddle: the particle schier in Austrian German. Wien. Linguist. Gaz. 82, 71-78.

Karttunen, L., 1972. Possible and must. In: Kimball, J. (Ed.), Syntax and Semantics, vol. 1. Academic Press, New York, pp. 1-20.

Knobe, J., Yalcin, S., 2014. Epistemic modals and context: experimental data. Semant. Pragmat. 7, 1-21.

Korotkova, N., 2016. Heterogeneity and Uniformity in the Evidential Domain. PhD dissertation. University of California, Los Angeles.

Kratzer, A., 1991. Modality. In: von Stechow, A., Wunderlich, D. (Eds.), Semantics: an International Handbook of Contemporary Research. de Gruyter, Berlin, pp. 639-650.

Lassiter, D., 2014. The weakness of must: in defense of a mantra. Semant. Ling. Theory 24, 597-618.

Lassiter, D., 2016. Must, knowledge, and (in)directness. Nat. Lang. Semant. 24, 117-163.

Mandelkern, M., 2017. Coordination in Conversation. PhD dissertation. MIT.

Matthewson, L., 2012. Evidence about evidentials: where fieldwork meets theory. In: Stolterfoht, B., Featherston, S. (Eds.), Empirical Approaches to Linguistic Theory: Studies of Meaning and Structure. de Gruyter, Berlin, pp. 85-114.

Matthewson, L., 2015. Evidential restrictions on epistemic modals. In: Alonso-Ovalle, L., Menéndez-Benito, P. (Eds.), Epistemic Indefinites. Exploring Modality Beyond the Verbal Domain. Oxford University Press, Oxford, pp. 141-160.

Matthewson, L., Truckenbrodt, H., 2017. Modal Flavour/Modal Force Interactions in German: Soll, Sollte, Muss and Müsste. Ms.

Murray, S., 2017. The Semantics of Evidentials. Oxford University Press, Oxford.

Salmon, W., 2011. Conventional implicature, presupposition, and the meaning of must. J. Pragmat. 43, 3416-3430.

Ünal, E., Papafragou, A., 2018. Evidentials, information sources, and cognition. In: Aikhenvald, A.Y. (Ed.), The Oxford Handbook of Evidentiality. Oxford University Press, Oxford, pp. 175-184.

von Fintel, K., Gillies, A.S., 2010. Must... stay... strong! Nat. Lang. Semant. 18, 351-383.

von Fintel, K., Gillies, A.S., 2016. Still Going Strong: the Semantics and Pragmatics of Epistemic Must. Ms.

Willett, T., 1988. A cross-linguistic survey of the grammaticalization of evidentiality. Stud. Lang. 12, 51-97.

Zimmermann, M., 2004. Zum wohl: Diskurspartikeln als Satztypmodifikatoren. Linguist. Ber. 199, 253-286.

Zimmermann, M., 2008. Discourse particles in the left periphery. In: Shaer, B., Cook, P., Frey, W., Maienborn, C. (Eds.), Dislocated Elements in Discourse: Syntactic, Semantic, and Pragmatic Perspectives. Routledge, New York \& London, pp. 200-231.

Zimmermann, M., 2011. Discourse particles. In: Portner, P., Maienborn, C., von Heusinger, K. (Eds.), Semantics: an International Handbook of Natural Language Meaning. Mouton de Gruyter, Berlin, pp. 2011-2038.

Dr. Judith Degen is Assistant Professor of Linguistics at Stanford University. Trained as a cognitive scientist at the University of Rochester and Stanford University, Judith is interested in the inference processes involved in language production and comprehension - how do speakers choose an utterance to convey an intended meaning? How do listeners arrive at interpretations that are often much richer and more detailed than the literal meaning provided by a sentence? She employs a combination of linguistic analysis, behavioral methods, corpus methods, and computational models to develop explicit theories of these processes and test them against behavioral data. 